\title{
Differentiation of the Chinese minority medicinal plant genus Berchemia spp. by evaluating three candidate barcodes
}

\author{
Li-Cheng Guo ${ }^{1,2}$, Ming-Ming Zhao ${ }^{3,4}$, Wei Sun ${ }^{3}$, Hong-Li Teng ${ }^{2}$, Bi-Sheng Huang ${ }^{1 *}$ and Xiang-Pei Zhao ${ }^{2}$
}

\begin{abstract}
The genus Berchemia comprises important Chinese plants with considerable medicinal value; however, these plants are often misidentified in the herbal medicinal market. To differentiate the various morphotypes of Berchemia species, a proficient method employing the screening of universal DNA barcodes was used in this work. Three candidate barcoding loci, namely, psbA-trnH, rbcL, and the second internal transcribed spacer (ITS2), were used to identify an effective DNA barcode that can differentiate the various Berchemia species. Additionally, PCR amplification, efficient sequencing, intra- and inter-specific divergences, and DNA barcoding gaps were employed to assess the ability of each barcode to identify these diverse Berchemia plants authentically; the species were differentiated using the Kimura two-parameter and maximum composite likelihood methods. Sequence data analysis showed that the ITS2 region was the most suitable candidate barcode and exhibited the highest interspecific divergence among the three DNA-barcoding sequences. A clear differentiation was observed at the species level, in which a maximum distance of 0.264 was exhibited between dissimilar species. Clustal analysis also demonstrated that ITS2 clearly differentiated the test species in a more effective manner than that with the two other barcodes at both the hybrid and variety levels. Results indicate that DNA barcoding is ideal for species-level identification of Berchemia and provides a foundation for further identification at the molecular level of other Rhamnaceae medicinal plants.
\end{abstract}

Keywords: Chinese minority medicinal plants, Berchimia spp., ITS2 DNA barcode, Species identification, Pairwise distance analysis

\section{Background}

Berchemia is a genus of plants in the Rhamnaceae family, which comprises 32 deciduous woody plants located in Asia, South America, and Africa (Huxley and Griffiths 1999). In China, Berchemia consists of 19 native species (Chen and Dong 2006), which are primarily distributed in the south, southwestern, and eastern regions (Sinicae 1988). These species include climbing plants or small- to medium-sized trees, several of which are endangered but offer significant medicinal values; these important plants include B. lineatai (Shen et al. 2010) and B. berchemiafolia (Kitamura and Murata 1984; Fu and Jin 1992; Ohwi 1984). In Japan, the roots, stems, and leaves

\footnotetext{
*Correspondence: hbsh1963@163.com

${ }^{1}$ Hubei University of Chinese Medicine, Wuhan 430065, China

Full list of author information is available at the end of the article
}

of Berchemia plants are used to treat liver diseases, neuralgia, and gall stones; furthermore, these parts are utilized in traditional Chinese medicine (Mukhtar et al. 2004).

The characteristics, transection structure, and powder properties of Berchemia species demonstrate obvious distinct features that can be used for microscopic identification. In particular, B. lineata, B. polyphylla, and B. polyphylla var. leioclada are closely related in terms of microstructure and microscopic characteristics. However, these three species can be distinguished on the basis of the characteristics of their leaf edge; the leaf edge cells of $B$. lineata are round, and the cell walls are not thickened, or thickening is not obvious. The leaf edge cells of B. polyphylla are square and rectangle, and the cell walls are obviously thickened. The leaf edge cells of B. polyphylla var. leioclada are round, and the cell walls 
show obvious thickening (Teng et al. 2010; Ye et al. 2013). These distinctions can provide a basis for the pharmacognostical identification of Berchemia species.

Berchemia species are highly similar in terms of apparent vegetative morphology and thus often misidentified. In Chinese herb markets, different species under the same name are sold as dried roots. Distinguishing these species merely by sight is impossible to the untrained eye. Although all the Berchemia species provide medicinal value, consuming a wrong one reduces drug efficiency and causes ill effects after prolonged usage. Therefore, the development of an accurate method to prove the authenticity of plant raw materials is necessary because traditional methods, including organoleptic trait evaluation and phytochemical and pharmacognostic methods, cannot accurately identify species (Yan et al. 2013).

DNA barcoding is a rapidly developing frontier technology that is gaining worldwide attention. This novel technology uses a standardized genomic DNA sequence from a standard locus as a species identification tool (Kress et al. 2005) and has become popular in species identification (Gregory 2005; Miller 2007). Barcoding is a convenient tool to identify species for nonprofessional users, such as traditional drug producers, forensic specialists, and customs officers (Xue and Li 2011). Numerous DNA barcodes exist in plants and animals, which can be used to identify species. CO1, which is used as a DNA barcode, is a powerful tool for the discrimination of closely related species in most animals (Hebert et al. 2003). In 2009, the Plant Working Group of the Consortium for the Barcode of Life (CBOL) recommended that the loci $r b c L+m a t K$ can be used as core barcodes to identify plants (CBOL Plant Working Group, 2009). The $p s b A$-trn $H$ intergenic spacer and internal transcribed spacer (ITS)/ITS2 were also suggested as barcodes for plant identification at the Third International Barcode Conference in Mexico City (Chen et al. 2010; Kress et al. 2005). Yao et al. (2010) proposed that the ITS2 locus, a popular phylogenetic marker, should be used as a universal DNA barcode and a complementary locus for CO1 to identify plants and animals, respectively (Yao et al. 2010). Pang et al. (2012) suggested that the tmH-psbA + ITS2 combination performs better or equally well in taxonomic groups, as compared with other combinations, such as $m a t K+r b c L$ (Pang et al. 2012).

The present work aimed to distinguish different Berchemia species by screening three candidate loci, namely, $r b c L, p s b A$-trn $H$, and ITS2, as the core barcodes and by identifying the most suitable barcode to accurately identify the members of the Berchemia genus. Furthermore, this study aimed to provide drug safety references for current medical fields.

\section{Results and discussion}

Amplification and sequence analysis

Genomic DNA was extracted from 55 samples belonging to seven species of Berchemia. The regions ITS2, $p s b A-\operatorname{trn} H$, and $r b c L$ underwent effective amplification for all the selected samples. All PCR products corresponding to these three barcodes were successfully sequenced, and high-quality bidirectional sequences were obtained. The PCR amplification size for ITS2, psbA-trnH, and $r b c L$ ranged within 491-561, 364-470, and 729-757 bp, respectively. Table 1 shows that the amplification efficiency of ITS2 and $r b c L$ was $100 \%$, and that of $p s b A-t r n H$ was $92 \%$. These results indicated that the three barcodes were applicable for the following analysis. ITS2 presented variable sites in 17/226 bp of the aligned sites, of which 11 were parsimonyinformative, whereas $p s b A$-trn $H$ and $r b c L$ showed very low variations of $6 / 430 \mathrm{bp}$ and $5 / 551 \mathrm{bp}$, respectively (Table 2).

Table 1 Amplification efficiency of $\mathbf{5 0}$ Berchemia samples using five selected markers

\begin{tabular}{llrrrr}
\hline & Samples & Quantity & ITS2 & psbA-trnH & $\boldsymbol{r b c L}$ \\
\hline & B. floribund & 10 & 10 & 9 & 10 \\
B. polyphylla & 10 & 10 & 9 & 10 \\
& B. sinica & 5 & 5 & 4 & 5 \\
& B. kulingensis & 5 & 5 & 5 & 5 \\
& B. polyphylla var. & 10 & 10 & 10 & 10 \\
& leioclada & & & & \\
& B. lineata & 10 & 10 & 9 & 10 \\
& B. hirtella & 5 & 5 & 5 & 5 \\
Total & 55 & 55 & 51 & 55 \\
Amplification & & 100 & 92 & 100 \\
efficiency (\%) & & & & \\
\hline
\end{tabular}

Table 2 Evaluation of the three DNA markers used in the present study

\begin{tabular}{llll}
\hline & $\boldsymbol{r b c L}$ & $\boldsymbol{p s b \boldsymbol { A } \text { trnH }}$ & ITS2 \\
\hline PCR success (\%) & 100 & 100 & 100 \\
Amplified product length (bp) & $729-757$ & $364-470$ & $491-561$ \\
Aligned sequence length (bp) & 551 & 430 & 226 \\
No. of variable sites & 5 & 6 & 13 \\
No. of Pi sites & 4 & 5 & 11 \\
No. of singletons & 1 & 0 & 2 \\
Inter specific distance mean & 0.001 & 0.002 & 0.026 \\
Total no. of clusters (UPGMA) & 3 & 3 & 4 \\
Identification efficiency (\%) & 15 & 50 & 100
\end{tabular}




\section{Pairwise distance analysis}

The mean interspecific genetic distances of the evaluated DNA regions are listed in Table 2. In the ITS2 region, the Berchemia interspecific distance mean was 0.026; however, the distance means of the two other candidate barcodes were $0.001(r b c L)$ and $0.002(p s b A-t r n H)$. The sequence data were further considered for pairwise distance analysis, and the ITS2 gene region was proven the most suitable for species differentiation (Table 2). In this study, the morphologically similar species $B$. kulingensis and B. polyphylla showed a distance of 0.009 . The three other morphologically similar species, namely, $B$. polyphylla, B. floribunda, and B. sinica, showed a distance of 0.014. Furthermore, the morphologically similar varieties of B. lineata and B. polyphylla var. leioclada showed a distance of 0.000 (Table 3).

\section{Clustal analysis}

In this study, 55 ITS2, 51 psbA-trnH, and 55 rbcL sequences were obtained from seven selected species. The five other sequences, two ITS2 sequences $(B$. hirtella HG004838; B. discolor AY626455), two rbcL sequences (B. hirtella KF181534; B. discolor JF265302), and a psbAtrnH sequence ( $B$. hirtella HG005084) were downloaded from GenBank. To evaluate the feasibility of the three candidate barcodes to differentiate the species, Clustal analysis was conducted using the neighbor-joining (NJ) method, and Ziziphus jujube belonging to Rhamnaceae was employed as outgroup. Following the phylogenetic analysis, the ITS2 region was clearly differentiated among all eight species. Overall, 21 selected ITS2 sequences from seven species and an ITS2 sequence belonging to another species obtained from the NCBI database were aligned in the NJ tree. As shown in Fig. 1a, each of the same species was divided into one group at the species level. Only the subspecies B. polyphylla var. leioclada was clustered to B. lineata. As shown in Fig. 1b, psbA-trnH differentiation was markedly inferior to ITS2. The $p s b A$ $\operatorname{trn} H$ barcode cannot distinguish all selected species. Most of them, including B. pollyphylla, B. kulingensi, B. lineata, B. sinica, and B. polyphylla var. leioclada, cannot be distinguished. The NJ trees according to the $r b c l$ sequences were expanded; only $B$. discolor and B. hirtella can be distinguished from the others (Fig. 1c). The $\mathrm{NJ}$ tree results indicated that $p s b A-\operatorname{trnH}$ and $r b c L$ were unsuitable for identification of Berchemia species. Only the ITS2 region was the most variable, and this sequence was adapted for further Clustal analysis. Both variable sites and deletions in the sequence information can be used to identify species (Jeanmougin et al. 1998).

Moreover, the variable sites played an important role in the identification of Berchemia. In this study, a deletion was found at site 44 in B. lineata, B. sinica, B. kulingensis, $B$. polyphylla, $B$. lineata, and B. polyphylla. Similarly, a deletion was detected at site 78 in B. lineata and B. polyphylla var. leioclada; $B$. hirtella also showed a deletion at site 17 (Fig. 2). Compared with the sequence regions of $B$. lineata and B. polyphylla var. leioclada, the other species of Berchemia showed variable C-A sites at 76 and C-T sites at 171 and 206. Additionally, the $B$. sinica sequence showed variable $\mathrm{T}-\mathrm{C}$ sites at 175 , whereas $B$. kulingensis showed variable $\mathrm{T}-\mathrm{C}$ sites at site 82 and $\mathrm{C}$ - $\mathrm{T}$ sites at 100 and 207. In addition, B. kulingensis and B. polyphylla showed variable A-G sites at site 207, B. floribunda showed variable $\mathrm{T}-\mathrm{C}$ sites at 178 , and $B$. hirtella showed variable C-G sites at 176 (Fig. 2).

\section{Barcoding gap}

To determine whether barcoding gap existed, we assessed the distribution of divergences in Berchemia (Fig. 3). The distribution and mean of intraspecific differences were lower than the interspecific divergences, with the highest significance found for ITS2. No obvious barcoding gaps were observed in $p s b A$-trn $H$ and $r b c L$. Thus, ITS2 can distinguish among Berchemia species.

Berchemia is a folk tradition medicinal plant with wide geographic distribution in Southwest China. The roots of B. lineata and other Berchemia species have been used as folk medicines to dispel wind and dampness, as well as invigorate blood circulation and analgesia. Additionally,

Table 3 Pairwise analysis of the ITS2 region using the Maximum Composite Likelihood method

\begin{tabular}{lllllll}
\hline & TB01 & DH02 & DY03 & KL04 & GE05 & GZ06 \\
\hline TB01 & & & & & \\
DH02 & 0.023 & & & & & \\
DY03 & 0.018 & 0.014 & & & & \\
KL04 & 0.028 & 0.023 & 0.009 & & & \\
GE05 & 0.023 & 0.018 & 0.014 & 0.023 & 0.028 & \\
GZ06 & 0.000 & 0.028 & 0.023 & 0.032 & 0.018 & \\
GB07 & 0.032 & 0.018 & 0.023 & 0.032 & 0.018 & \\
\hline
\end{tabular}




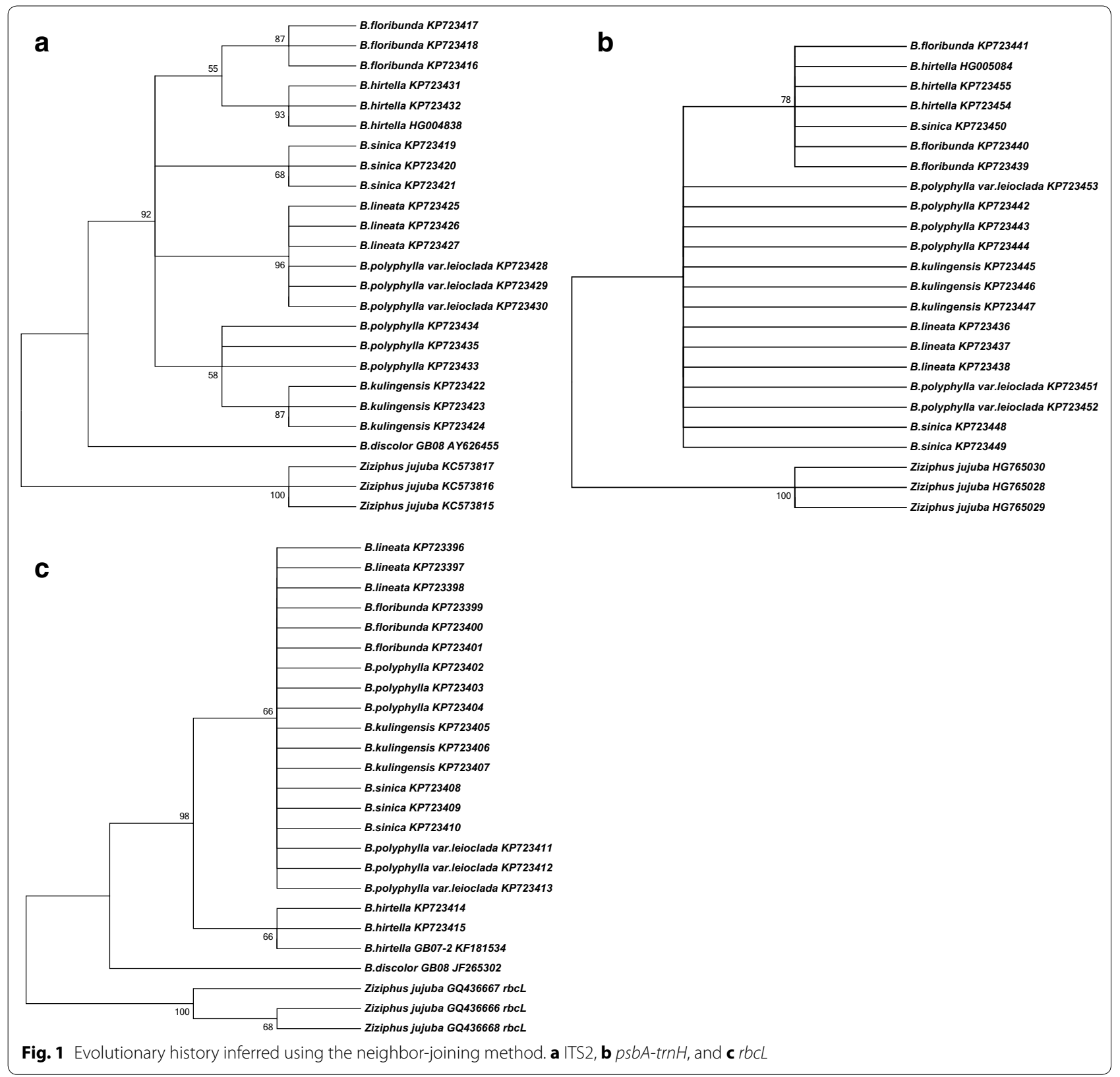

these plants exhibit antitumor, anti-rheumatic, antimicrobial, hepatoprotective, and anti-inflammatory properties (Shen et al. 2010). Currently, B. lineata and $B$. polyphylla var. leioclada are the two primary varieties in herbal medicine markets, and they are traditionally called "Tiebaojin" in specific areas (Yan et al. 2013). However, most of the Berchemia species are commonly used as "Tiebaojin" in herbal medicine markets because of their morphological similarity among one another. Furthermore, these plants are typically sold as decoction pieces in the market, which makes morphological analysis difficult to implement once the plants are dried. To ensure food and drug safety, studies have aimed to select a practical and powerful tool to authenticate closely related species. To date, existing methods such as microscopic identification and HPLC fingerprinting cannot effectively distinguish Berchemia species (Yan et al. 2013). Therefore, a molecule-based method should be developed.

In this work, DNA barcoding was used to distinguish among eight common and folk medicinal plants of Berchemia. The plant mat $K$ barcode recommended by 


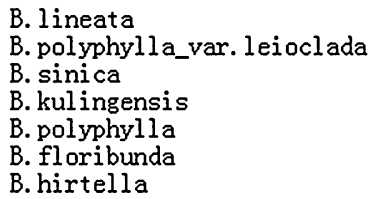

B. lineata

B. polyphylla_var. leioclada

B. sinica

B. kul ingensis

B. polyphylla

B. floribunda

B. hirtella

B. lineata

B. polyphylla_var. leioclada

B. sinica

B. kulingensis

B. polyphylla

B. floribunda

B. hirtella
$111111111122222222223333333333444444444455555555556 \quad 6666666667 \quad 7777777778$ ] 12345678901234567890123456789012345678901234567890123456789012345678901234567890 CACAACGTTG CCCCCCCAAC CCCAAACCTC GACTTCGAGG A-GGACGGGG GGCGGATTCT GGCCTCCCGT GCGCCCCCGG

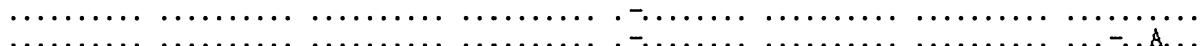

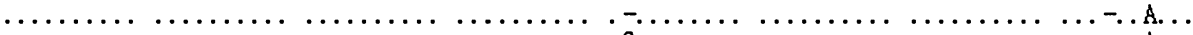

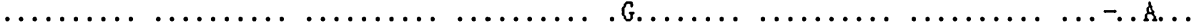

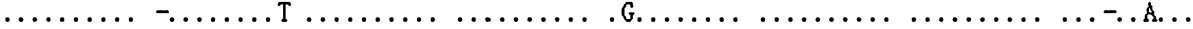

$111111111111111111111111111111111111111111111111111 \quad 1111111111$ $888888888999999999900000000001 \quad 1111111112 \quad 2222222223 \quad 33333333344444444445 \quad 5555555556$ 12345678901234567890123456789012345678901234567890123456789012345678901234567890 CTCGCGGTTG GCCCAAATGC GAGTACTCGG CGACGAGCGC CGCGGCAATC GGTGGTTGTC CAACCCTCGG TGCCATGCTG

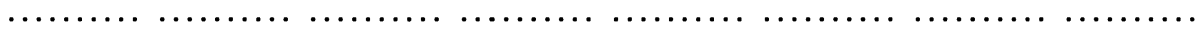

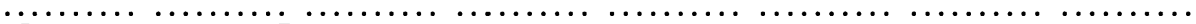

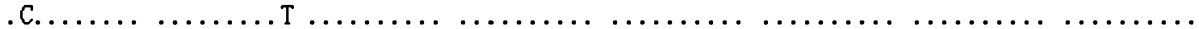

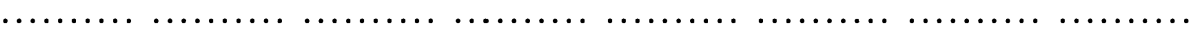

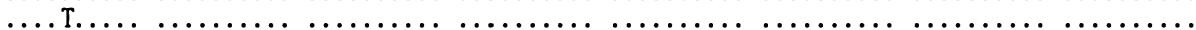
... T

111111111111111111111111111111111111111222222222222222222222 22222]

$6666666667 \quad 7777777778 \quad 88888888899999999990 \quad 0000000001 \quad 1111111112 \quad 22222]$

$\begin{array}{llllllll}1234567890 & 1234567890 & 1234567890 & 1234567890 & 1234567890 & 1234567890 & 12345]\end{array}$

CGAGCGCGAG CCGCTCATCG TTACTCGTCG ACCCCCAACG CGCCGCACAC ACGGCGTTCA CAACG

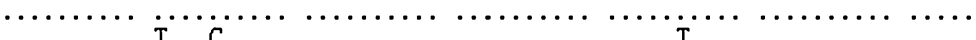

$\ldots \ldots \ldots \ldots$ т...С................................

$\ldots \ldots \ldots \ldots$ T.......................... TG.............

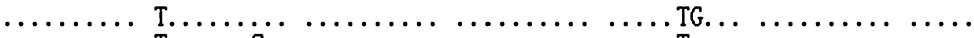

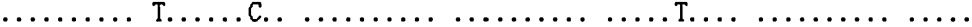

n...... T....G....................................

Fig. 2 The complete alignment matrix of the Berchemia ITS2 sequences
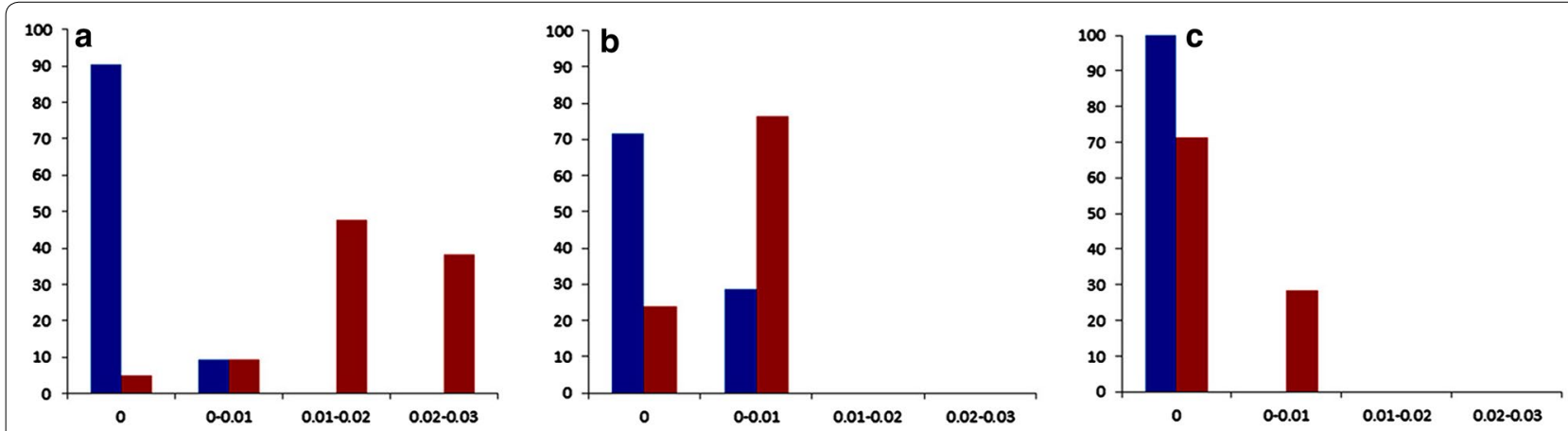

Fig. 3 Relative distribution of inter-specific divergence and intra-specific variation of three barcodes a ITS2, b psbA-trnH, and $\mathbf{c} r b c L$, Blue color intraspecific, Red color inter-specific

CBOL was excluded because of its low amplification rate. Thus, we used the ITS2, $p s b A-\operatorname{trn} H$, and $r b c L$ regions of nuclear ribosomal DNA to examine a total of 56 samples belonging to eight Berchemia species (B. discolor sequences were obtained from the NCBI nucleotide database). Among the candidate DNA barcodes, the rate of successful identification with ITS2 was $100 \%$ at the species level. Our results highlighted the advantages of using the ITS2 region as a DNA barcode; these advantages include universality, small intraspecific variation but high interspecific divergence, and a small fragment length of approximately $200 \mathrm{bp}$ (Chen et al. 2010). These advantages lead to easy amplification and sequencing (Sun and Chen 2013).

Our study suggested the ITS2 region as the most ideal for Berchemia species identification. Pairwise distance analysis validated Berchemia, irrespective of the morphological similarities of several subspecies; nevertheless, the analysis failed to validate all the subspecies. Among the varieties $B$. lineata and B. polyphylla var. leioclada, a distance value of zero showed that the ITS2 region cannot differentiate the varieties of these species. Therefore, as indicated by the high degree of sequence variation, the pairwise distance analysis was proven 
useful in Berchemia identification but only up to the species level.

The NJ tree is useful in the identification of most of the species through the formation of monophyletic groups; this tool is also helpful in studying the ancestry and taxonomic positions of some species (Zhou et al. 2008). An issue of concern involves plant taxonomy because $B$. polyphylla var. leioclada belongs to the B. polyphylla subspecies, but it groups with $B$. lineata. We assumed that $B$. polyphylla may be a variation of $B$. lineata because they demonstrate a very close phylogenetic relationship. This phenomenon indicates that although the two species exhibit a similar morphological appearance, they may not present a close phylogenetic relationship. Hence, species identification at the molecular level is more convenient and efficient.

Clustal analysis is an essential tool used in barcoding (Higgins et al. 1992). In this study, deletion and variable site analysis showed that no barcode was able to differentiate among Berchemia spp. at the variation species level, even the ITS2 sequence. With regard to the variation in Berchemia spp., in which identification cannot also be achieved via morphological means, other methods can be attempted, such as phytochemical analysis. As previously reported, the quercetin and rutin levels differed between B. lineata and B. polyphylla var. leioclada. Specifically, $B$. lineata contains more quercetin and less rutin than $B$. polyphylla var. leioclada (Guo et al. 2012).

Ideally, barcodes must exhibit a barcoding gap between interspecific and intraspecific divergences (Meyer and Paulay 2005; Newmaster et al. 2006). To determine the existence of a gap, we assessed the distribution of divergences in classes of 0.001 distance units. The distribution and mean of intraspecific differences were lower than those of interspecific divergences; the highest significance levels were found for ITS2, followed by $p s b A-\operatorname{trn} H$ and $r b c L$. The differential efficiency of ITS2 was more effective than that of $p s b A-t r n H$ and $r b c L$ and more suitable for Berchemia spp. in barcode identification. Phylogenetic analysis also showed that $r b c L$ and $p s b A$-trn $H$ were not ideal barcodes in this identification process. The markers mentioned above all belong to the chloroplast genome, hence indicating that these chloroplast genome barcodes may not be suitable for Berchemia species identification. Whether this principle can be applied to the identification of other Rhamnaceae plants should be further determined.

\section{Conclusions}

This study demonstrated that DNA barcoding is an effective and useful tool to identify and track various raw materials of Berchemia medicinal plants in a cost-effective and efficient manner. This finding also elucidates several taxonomic conflicts among morphologically similar species in the Chinese herb market and provides candidate barcodes for further identification of other Chinese medicinal plants.

\section{Methods}

\section{Sampling of plant materials}

A total of 55 samples belonging to seven species (Fig. 4), namely, B. floribunda, B. polyphylla, B. sinica, B. kulingensis, $B$. polyphylla var. leioclada, $B$. hirella, and $B$. lineata, were sampled from the Guangxi, Guizhou, and Yunnan provinces in China (Table 4). We collected at least three samples for every species. The voucher samples were deposited in the herbarium at the Guangxi Institute of Minority Medicine, Nanning, China. In addition, two Berchemia raw material samples were purchased from a local supermarket and pharmacy. Two

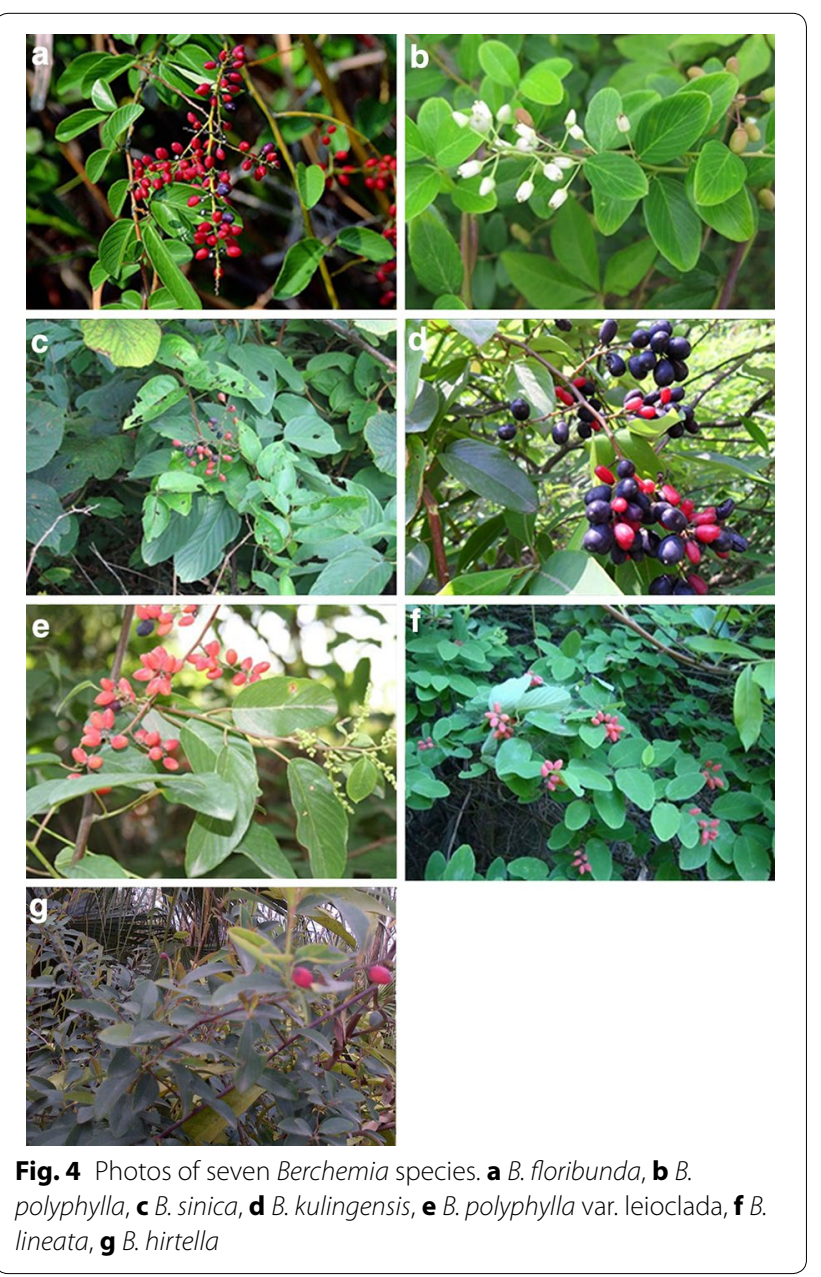


Table 4 Specimen voucher, date of collection and Accession numbers of the seven Berchemia species

\begin{tabular}{|c|c|c|c|c|}
\hline Specimen & Specimen voucher no. & Collection locality & Latitude, and longitude & Date of collection \\
\hline \multirow[t]{10}{*}{ Berchemia lineata } & Gmm101 & Wuming, Guangxi, China & $23.2775,108.0265$ & 2-Apr-2013 \\
\hline & Gmm102 & Nanning, Guangxi, China & $22.9704,108.3643$ & 11-Mar-2013 \\
\hline & Gmm103 & Fenghuang, Guangxi, China & $23.1483,108.2550$ & 4-Oct-2013 \\
\hline & Gmm104 & Fangcheng, Guangxi, China & $21.5296,108.1716$ & 15-Aug-2013 \\
\hline & Gmm105 & Shibing, Guizhou, China & $27.1979,107.9362$ & 10-Set-2013 \\
\hline & Gmm106 & Longli, Guizhou, China & $26.4236,106.9669$ & 12-Feb-2013 \\
\hline & Gmm107 & Pumiao, Guangxi, China & $22.6459,108.6089$ & 9-Dec-2013 \\
\hline & Gmm108 & Tianguan, Guangxi, China & $23.8328,107.3451$ & 25-Mar-2013 \\
\hline & Gmm109 & Kunming, Yunnan, China & $25.1466,102.7489$ & 8-May-2013 \\
\hline & Gmm110 & Shennongjia, Hubei, China & $31.5018,110.2811$ & 19-Apr-2014 \\
\hline \multirow[t]{10}{*}{ B. floribunda } & Gmm201 & Hezhou, Guangxi, China & $24.4493,111.6069$ & 3-Mar-2013 \\
\hline & Gmm202 & Shatian, Guangxi, China & $24.3048,111.4503$ & 11-Apr-2013 \\
\hline & Gmm203 & Pingguo, Guangxi, China & $23.3318,107.6717$ & 17-May-2013 \\
\hline & Gmm204 & Liuzhou, Guangxi, China & $24.3065,109.0040$ & 18-Nov-2013 \\
\hline & Gmm205 & Lianhua, Guangxi, China & $24.1594,110.1244$ & 13-Aug-2013 \\
\hline & Gmm206 & Jinxiu, Guangxi, China & $24.1228,110.2234$ & 8-Jun-2013 \\
\hline & Gmm207 & Baise, Guangxi, China & $23.6189,106.6550$ & 28-Oct-2013 \\
\hline & Gmm208 & Tianguan, Guangxi, China & $23.8686,107.3752$ & 19-Dec-2013 \\
\hline & Gmm209 & Kunming, Yunnan, China & $21.9219,101.2792$ & 2-Sep-2013 \\
\hline & Gmm210 & Shennongjia, Hubei, China & $31.4790,110.4053$ & 11-Jul-2014 \\
\hline \multirow[t]{10}{*}{ B. polyphylla } & Gmm301 & Mashan, Guangxi, China & $23.7286,108.2027$ & 7-Apr-2013 \\
\hline & Gmm302 & Napo, Guangxi, China & $23.3947,105.8710$ & 10-May -2013 \\
\hline & Gmm303 & Puding, Guizzhou, China & $26.3777,105.8509$ & 4-Jun-2013 \\
\hline & Gmm304 & Wuming, Guangxi, China & $23.2866,108.0720$ & 18-May -2013 \\
\hline & Gmm305 & Nanning, Guangxi, China & $22.9698,108.3574$ & 20-Feb-2013 \\
\hline & Gmm306 & Tianguan, Guangxi, China & $23.8339,107.2563$ & 27-Apr-2013 \\
\hline & Gmm307 & Baise, Guangxi, China & $23.7412,106.4356$ & 18-Nov-2013 \\
\hline & Gmm308 & Shennongjia, Hubei, China & $31.4569,110.4266$ & 21-Sep-2013 \\
\hline & Gmm309 & Kunming, Yunnan, China & $25.1463,102.7499$ & 9-Mar-2014 \\
\hline & Gmm310 & Pingguo, Guangxi, China & $23.3537,107.9895$ & 12-Jan-2014 \\
\hline \multirow[t]{5}{*}{ B. kulingensis } & Gmm401 & Shibing, Guizhou, China & $27.0124,108.1447$ & 18-May -2013 \\
\hline & Gmm402 & Lushan, Jiangxi, China & $29.5808,115.9856$ & 18-May -2013 \\
\hline & Gmm403 & Kunming, Yunnan, China & $25.1462,102.7490$ & 18-May -2013 \\
\hline & Gmm404 & Napo, Guangxi, China & $23.3984,105.8189$ & 18-May -2013 \\
\hline & Gmm405 & Jingxi, Guangxi, China & $23.1634,106.3467$ & 18-May -2013 \\
\hline \multirow[t]{5}{*}{ B. sinica } & Gmm501 & Kunming, Yunnan, China & $25.1460,102.7492$ & 24-Sep-2013 \\
\hline & Gmm502 & Longli, Guizhou, China & $26.4224,106.9686$ & 9-Dec-2013 \\
\hline & Gmm503 & Zuoshui, Guizhou, China & $33.8007,108.9149$ & 22-Feb-2014 \\
\hline & Gmm504 & Shennongjia, Hubei, China & $31.4697,110.3871$ & 12-May-2104 \\
\hline & Gmm505 & Guangzhou, Guangdong, China & $23.1840,113.3672$ & 15-Mar-2014 \\
\hline \multirow[t]{9}{*}{ B. polyphylla var. leioclada } & Gmm601 & Fusui, Guangxi, China & $22.6160,107.9188$ & 6-Mar-2013 \\
\hline & Gmm602 & Jingxi, Guangxi, China & $23.0306,106.6587$ & 12-Dec-2013 \\
\hline & Gmm603 & Nanning, Guangxi, China & $22.9765,108.3466$ & 9-Mar-2013 \\
\hline & Gmm604 & Wuming, Guangxi, China & $23.0428,108.3025$ & 6-Jun-2013 \\
\hline & Gmm605 & Huashan, Guangxi, China & $23.0338,108.3008$ & 16-Jun-2013 \\
\hline & Gmm606 & Pumiao, Guangxi, China & $22.7054,108.5059$ & 8-Sep-2013 \\
\hline & Gmm607 & Basang, Guangxi, China & $22.6133,107.7846$ & 12-Oct-2013 \\
\hline & Gmm608 & Shibing, Guizhou, China & $27.1034,108.1265$ & 2-Jul-2013 \\
\hline & Gmm609 & Mashan, Guangxi, China & $23.6769,108.2725$ & 4-Aug-2013 \\
\hline
\end{tabular}


Table 4 continued

\begin{tabular}{lllll}
\hline Specimen & Specimen voucher no. & Collection locality & Latitude, and longitude & Date of collection \\
\hline \multirow{3}{*}{ B. hirtella } & Gmm610 & Hezhou, Guangxi, China & $24.3172,111.4549$ & $29-$ May-2013 \\
& Gmm701 & Kunming, Yunnan, China & $25.1461,102.7497$ & $13-J u n-2013$ \\
& Gmm702 & Jingdong, Yunnan, China & $24.3963,100.7885$ & $10-M a r-2013$ \\
& Gmm703 & Ruili, Yunnan, China & $24.0143,97.8245$ & $8-$ May-2013 \\
& Gmm704 & Zhenkang, Yunnan, China & $23.7687,98.8248$ & $22-$ Sep-2013 \\
& Gmm705 & Menghai, Yunnan, China & $21.9820,100.466$ & $18-$ Aug-2014 \\
\hline
\end{tabular}

additional sequences belonging to $B$. dicolor were downloaded from the NCBI GenBank and used for comparative studies with the omission of accessions for identical sequence information. All the samples were identified by Liu Shou-yang, a botanist from Guangxi University of Chinese Medicine.

\section{DNA extraction}

Total genomic DNA was extracted from approximately $30-40 \mathrm{mg}$ of dried leaves or $60-70 \mathrm{mg}$ of roots, which were homogenized at $30 \mathrm{~Hz}$ with two stainless steel ball bearings in a 2.0 centrifuge tube by using the Plant Genomic DNA Kit (Tiangen Biotech Co., Beijing, China) in accordance with the manufacturer's protocol. The sample powder was incubated at $65{ }^{\circ} \mathrm{C}$ in $750 \mu \mathrm{L}$ of GP1 buffer. The incubation time was extended from $20 \mathrm{~min}$ to $1 \mathrm{~h}$ for dried leaves or up to $5 \mathrm{~h}$ for roots and rhizomes. The remaining steps followed the manufacturer's instructions.

\section{DNA amplification and sequencing}

PCR was performed using the universal barcode forward and reverse primers for the ITS2, psbA-trnH, and $r b c L$ regions (Table 5) (Kress et al. 2005; Lahaye et al. 2008; Sass et al. 2007; Song et al. 2009). General PCR conditions were adopted, as shown in Table 5 (Chen et al. 2010; Sui et al. 2011). Individual amplifications were performed in $25 \mu \mathrm{L}$ of a reaction mixture containing $2 \times$ Tag PCR Master Mix (12.5 $\mu \mathrm{L}$, Aidlab Biotechnologies Co., Beijing, China), $1 \mu \mathrm{L}$ of each primer $(2.5 \mu \mathrm{mol} / \mathrm{L})$, and double-distilled water $(8.5 \mu \mathrm{L})$. Approximately $4 \mu \mathrm{L}$ of PCR products were examined by $1.0 \%$ agarose gel electrophoresis (Fig. 5) and purified using the TIANgel Midi Purification Kit (Tiangen Biotech Co., Beijing, China). The purified PCR products were sequenced using an ABI3730XL sequencer (Applied Biosystems, Foster City, CA) with the amplification primers. All sequence data were submitted to NCBI, and accession numbers were obtained (Table 6).

\section{Data analysis}

Sequence assembly and generation of consensus sequences were completed using CodonCode Aligner v3.7 (CodonCode Corp., Dedham, MA, USA). The traces were assembled into bidirectional contigs, primer sequences were removed, and all ambiguous base calls were checked manually. Contigs were compared using the MUSCLE multiple sequence alignment algorithms supplemented with the CodonCode Aligner. Genetic variations were analyzed with a Kimura 2-parameter distance matrix, which was constructed using MEGA5.0 software (Ma et al. 2014) and ClustalW (Sun and Chen 2013). A phylogenetic tree was created using the NJ method. Bootstrap test with 1000 replicates was applied to assess the reliability of the phylogenetic trees (Tamura

Table 5 List of universal primers and reaction conditions for candidate barcodes

\begin{tabular}{|c|c|c|c|c|}
\hline Marker & $\begin{array}{l}\text { Name of } \\
\text { primers }\end{array}$ & Primer sequences $5^{\prime}-3^{\prime}$ & PCR conditions & $\begin{array}{l}\text { Production expected } \\
\text { length (bp) }\end{array}$ \\
\hline ITS2 & $\begin{array}{l}\text { S2F } \\
\text { S3R }\end{array}$ & $\begin{array}{l}\text { ATGCGATACTTGGTGTGAAT } \\
\text { GACGCTTCTCCAGACTACAAT }\end{array}$ & $\begin{array}{l}94^{\circ} \mathrm{C} 5 \mathrm{~min} \\
94^{\circ} \mathrm{C} 30 \mathrm{~s}, 56{ }^{\circ} \mathrm{C} 30 \mathrm{~s}, 72{ }^{\circ} \mathrm{C} 45 \mathrm{~s}, 40 \text { cycles, } 72{ }^{\circ} \mathrm{C} 10 \mathrm{~min}\end{array}$ & $491-561$ \\
\hline$r b c L$ & $\begin{array}{l}1 f \\
724 r\end{array}$ & $\begin{array}{l}\text { ATGTCACCACAAACAGAAAC } \\
\text { TCGCATGTACCTGCAGTAGC }\end{array}$ & $\begin{array}{l}95^{\circ} \mathrm{C} 2 \mathrm{~min} \\
94^{\circ} \mathrm{C} 1 \mathrm{~min}, 55^{\circ} \mathrm{C} 30 \mathrm{~s}, 72^{\circ} \mathrm{C} 1 \mathrm{~min}, 34 \text { cycles, } 72^{\circ} \mathrm{C} \\
7 \mathrm{~min}\end{array}$ & $729-757$ \\
\hline psbA-trnH & $\begin{array}{l}\text { fwd PA } \\
\text { rev TH }\end{array}$ & $\begin{array}{l}\text { GTTATGCATGAACGTAATGCTC } \\
\text { CGCGCATGGTGGATTCACAATCC }\end{array}$ & $\begin{array}{l}94^{\circ} \mathrm{C} 5 \min \\
94{ }^{\circ} \mathrm{C} 1 \min , 55^{\circ} \mathrm{C} 1 \mathrm{~min}, 72^{\circ} \mathrm{C} 1.5 \mathrm{~min}, 30 \text { cycles, } 72{ }^{\circ} \mathrm{C} \\
\quad 7 \min \end{array}$ & $364-470$ \\
\hline
\end{tabular}




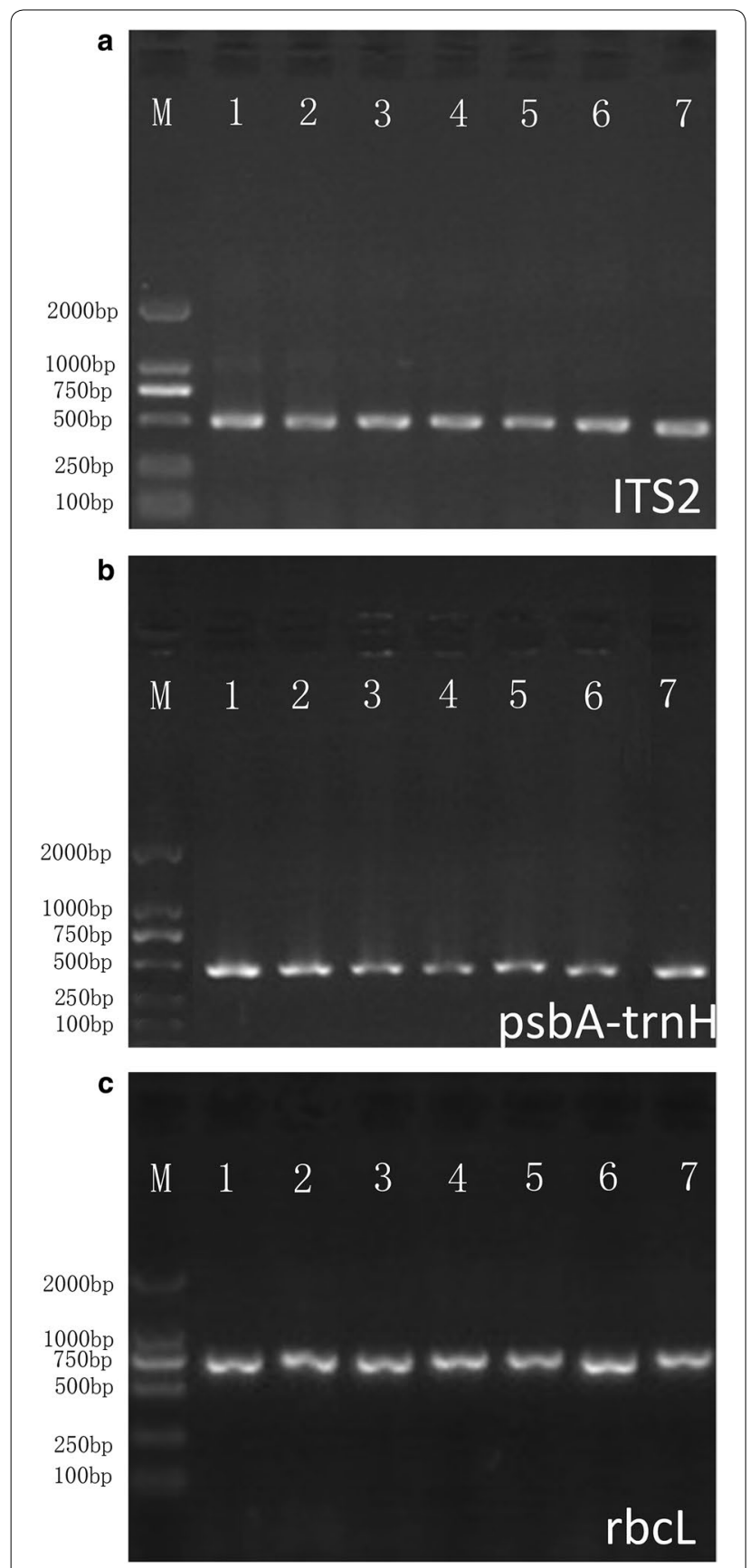

Fig. 5 Agarose gel electrophoresis analysis of three PCR products amplified using the primers of ITS2 (a), psbA-trnH (b) , and $r b c L(\mathbf{c})$

et al. 2011). The inter/intraspecific variations of the samples were calculated as described by Kress et al. (2005) and Song et al. (2009). The obtained sequences were also
Table 6 NCBI Accession numbers of the ITS2, psbA-trnH and $r b c L$ regions of the obtained six Berchemia species and a variety Berchemia species

\begin{tabular}{lllll}
\hline Samples name & Specimen ID & Genbank accession no. \\
\cline { 3 - 5 } & & ITS2 & psbA-trnH & rbcL \\
\hline B. lineata & TB01 & KP723425 & KP723436 & KP723396 \\
& TB01-1 & KP723426 & KP723437 & KP723397 \\
& TB01-2 & KP723427 & KP723438 & KP723398 \\
B. floribunda & DH02 & KP723416 & KP723439 & KP723399 \\
& DH02-1 & KP723417 & KP723440 & KP723400 \\
& DH02-2 & KP723418 & KP723441 & KP723401 \\
B. polyphylla & DY03 & KP723433 & KP723442 & KP723402 \\
& DY03-1 & KP723434 & KP723443 & KP723403 \\
B. kulingensis & DY03-2 & KP723435 & KP723444 & KP723404 \\
& KL04 & KP723422 & KP723445 & KP723405 \\
& KL04-1 & KP723423 & KP723446 & KP723406 \\
B. sinica & KL04-2 & KP723424 & KP723447 & KP723407 \\
& GE05 & KP723419 & KP723448 & KP723408 \\
& GE05-1 & KP723420 & KP723449 & KP723409 \\
B. polyphylla var. & GE05-2 & KP723421 & KP723450 & KP723410 \\
leioclada & GZ06 & KP723428 & KP723451 & KP723411 \\
& GZ06-1 & KP723429 & KP723452 & KP723412 \\
B. hirtella & GZ06-2 & KP723430 & KP723453 & KP723413 \\
& GB07 & KP723431 & KP723454 & KP723414 \\
& GB07-1 & KP723432 & KP723455 & KP723415 \\
& GB07-2 & HG004838 & HG005084 & KF181534 \\
\hline & & & & \\
& & & &
\end{tabular}

compared with the existing Berchemia species sequences obtained from the NCBI database through BLASTn test (Chen et al. 2010; Ross et al. 2008).

\section{Authors' contributions}

$\mathrm{TH}$ and $\mathrm{HB}$ conceived the study, participated in its design and coordination, and helped in drafting the manuscript. GL and ZM performed majority of the experimental work. ZX and SW participated in the sequence alignment. All authors have read and approved the final manuscript.

\section{Author details}

${ }^{1}$ Hubei University of Chinese Medicine, Wuhan 430065, China. ${ }^{2}$ Guangxi Institute of Minority Medicine, Nanning 530001, China. ${ }^{3}$ Institute of Chinese Materia Medica, China Academy of Chinese Medical Sciences, Beijing 100700, China. ${ }^{4}$ Medical Laboratory College, Beihua University, Jilin 132013, China.

\section{Acknowledgements}

This study was supported by the National Natural Science Foundation of Guangxi, China (No. 2013GXNSFDA019023) and the Science and Technology of Traditional Chinese Medicine of Guangxi, China (No. GZBZ16-14).

\section{Competing interests}

The authors declare that they have no competing interests.

Received: 6 November 2015 Accepted: 21 April 2016

Published online: 03 June 2016 


\section{References}

Chen L, Dong JX (2006) Advances in studies on chemical constituents from plants of Berchemia Neck and their bioactivities. Chin Tradit Herb Drugs 37(4):627 (in chinese)

Chen S, Yao H, Han J, Liu C, Song J, Shi L et al (2010) Validation of the ITS2 region as a novel DNA barcode for identifying medicinal plant species. PLoS One 5(1):e8613

Fu LK, Jin JM (1992) China plant red data book—rare and endangered plants, vol 1. Science Press, pp 312-319

Gregory TR (2005) DNA barcoding does not compete with taxonomy. Nature 434(7037):1067-1067

Guo LC, Teng HL, Mei ZN (2012) TLC identification and determination of the quercetin in Berchemia lineata. Lishizhen MedMateria Medica Res 12:016 (in chinese)

Hebert PD, Ratnasingham S, de Waard JR (2003) Barcoding animal life: cytochrome c oxidase subunit 1 divergences among closely related species. Proc R Soc Lond B Biol Sci 270(Suppl 1):S96-S99

Higgins DG, Bleasby AJ, Fuchs R (1992) CLUSTAL V: improved software for multiple sequence alignment. Comput Appl Biosci CABIOS 8(2):189-191

Huxley AJ, Griffiths M (1999) The new royal horticultural society dictionary of gardening. Groves Dictionaries Inc, New York

Jeanmougin F, Thompson JD, Gouy M, Higgins DG, Gibson TJ (1998) Multiple sequence alignment with Clustal X. Trends Biochem Sci 23(10):403-405

Kitamura S, Murata G (1984) Colored illustrations of woody plants of Japan, vol 1. Horikusha Pub. Co., In, Osaka

Kress WJ, Wurdack KJ, Zimmer EA, Weigt LA, Janzen DH (2005) Use of DNA barcodes to identify flowering plants. Proc Natl Acad Sci USA 102(23):8369-8374

Lahaye R, Van der Bank M, Bogarin D, Warner J, Pupulin F, Gigot G et al (2008) DNA barcoding the floras of biodiversity hotspots. Proc Natl Acad Sci USA 105(8):2923-2928

Ma X, Xie C, Guan M, Xu X, Miki E, Takeda O et al (2014) High levels of genetic diversity within one population of rheum tanguti-cum on the QinghaiTibet plateau have implications for germplasm conservation. Pharm Crop 5:1-8

Meyer CP, Paulay G (2005) DNA barcoding: error rates based on comprehensive sampling. PLoS Biol 3(12):e422

Miller SE (2007) Coding and the renaissance of taxonomy. Proc Natl Acad Sci USA 104(12):4775-4776

Mukhtar N, Malik A, Riaz N, labal K, Tareen RB, Khan SN et al (2004) Pakistolides $A$ and $B$, novel enzyme inhibitory and antioxidant dimeric 4-(glucosyloxy) benzoates from Berchemia pakistanica. Helv Chim Acta 87(2):416-424

Newmaster S, Fazekas A, Ragupathy S (2006) DNA barcoding in land plants: evaluation of rbcL in a multigene tiered approach. Botany 84(3):335-341
Ohwi J (1984) Flora of Japan. A combined much revised, and extended translation by the author of his Flora of Japan (1953) and Flora of Japan: Pteridophyta (1957). Smithsonian Institution, Washington

Pang X, Liu C, Shi L, Liu R, Liang D, Li H et al (2012) Utility of the trnH-psbA intergenic spacer region and its combinations as plant DNA barcodes: a meta-analysis. PLoS One 7(11):e48833

Ross HA, Murugan S, Li WLS (2008) Testing the reliability of genetic methods of species identification via simulation. Syst Biol 57(2):216-230

Sass C, Little DP, Stevenson DW, Specht CD (2007) DNA barcoding in the cycadales: testing the potential of proposed barcoding markers for species identification of cycads. PLoS One 2(11):e1154

Shen YX, Teng HL, Yang GZ, Mei ZN, Chen XL (2010) A new chromone derivative from Berchemia lineata. Acta Pharmacol Sin 45(9):1139-1143

Sinicae FRP (1988) Tomus 72, Delectis Florae Reipublicae Popularis Sinicae Agendae Academiae Sinicae Edita. Science Press, In.

Song J, Yao H, Li Y, Li X, Lin Y, Liu C et al (2009) Authentication of the family Polygonaceae in Chinese pharmacopoeia by DNA barcoding technique. J Ethnopharmacol 124(3):434-439

Sui XY, Huang Y, Tan Y, Guo Y, Long CL (2011) Molecular authentication of the ethnomedicinal plant Sabia parviflora and its adulterants by DNA barcoding technique. Planta Med Nat Prod Med Plant Res 77:492

Sun Z, Chen S (2013) Identification of cortex herbs using the DNA barcode nrlTS2. J Nat Med 67(2):296-302

Tamura K, Peterson D, Peterson N, Stecher G, Nei M, Kumar S (2011) MEGA5: molecular evolutionary genetics analysis using maximum likelihood, evolutionary distance, and maximum parsimony methods. Mol Biol Evol 28(10):2731-2739

Teng H, Chen K, Chen S (2010) The species basis of Berchemia lineata and its drug commodity. Zhong Yao Cai 33(5):674-677 (in chinese)

Xue CY, Li DZ (2011) Use of DNA barcode sensu lato to identify traditional Tibetan medicinal plant Gentianopsis paludosa (Gentianaceae). J Syst Evol 49:267-270

Yan H, Li Y, Zhang H, He M (2013) Pharmacognostical study on Berchemia floribunda. Zhong Yao Cai 36(6):908-910 (in chinese)

Yao H, Song J, Liu C, Luo K, Han J, Li Y et al (2010) Use of ITS2 region as the universal DNA barcode for plants and animals. PLoS One 5(10):e13102

Ye Y, He M, Li D, Xiong Y, Yan H (2013) Primary study on dormancy and release method for Berchemia lineata seed. Zhong Yao Cai 36(9):1385-1389 (in chinese)

Zhou J, Sun J, Xu S, Zhou Q, Sun S (2008) Study on the identification of Illicium vatum Hook. f. and illicium lanceolatum AC Smith by multi-ateps infrared macro-fingerprint method. Guang Pu Xue Yu Guang Pu Fen Xi 28:2864-2867

\section{Submit your manuscript to a SpringerOpen ${ }^{\circ}$ journal and benefit from:}

- Convenient online submission

- Rigorous peer review

- Immediate publication on acceptance

- Open access: articles freely available online

- High visibility within the field

- Retaining the copyright to your article

Submit your next manuscript at springeropen.com 